\title{
PERKAWINAN POLITIK DAN INTEgRASI DI SULAWESI SELATAN ABAD XVII-XVIII
}

\section{THE POLITICAL MARRIAGE AND INTEGRATION IN SOUTH SULAWESI XVII- XVIII CENTURY}

\author{
Rismawidiawati \\ Balai Pelestarian Nilai Budaya Makassar \\ e-mail: rismawidiawati@yahoo.co.id
}

\begin{abstract}
Abstrak
Pasca perjanjian Bungaya 1667, perkawinan politik digunakan sebagai salah satu strategi dalam membangun kekuatan. Strategi ini bukanlah hal baru dalam sejarah panjang Sulawesi Selatan. Sejak dahulu strategi ini juga dilakukan, oleh para bangsawan Bugis-Makassar yang berhasil menanamkan kekuasaan di wilayah lain. Namun demikian, perkawinan politik yang terjadi pasca Perjanjian Bungaya adalah perkawinan politik yang dilakukan antara kerajaan yang bertujuan membina ikatan kekerabatan yang luas untuk akhirnya membangun kebersamaan dalam rangka membangun kekuatan. Perkawinan politik tidak saja terjadi antara dua insan dari keluarga jauh, tetapi juga dilakukan antara dua insan yang masih memiliki hubungan keluarga dekat, yaitu sepupu satu kali, dua kali dan sepupu tiga kali.Strategi ini ditempuh karena perkawinan bagi orang Bugis-Makassar, bermakna saling mengambil satu sama lain. Perkawinan tidak melibatkan lakilaki dan perempuan yang kawin saja, melainkan kerabat kedua belah pihak dengan tujuan memperbaharui dan memperkuat hubungan keduanya. Perkawinan politik akhirnya membuahkan hasil dengan terjadinya integrasi di Sulawesi Selatan.Tulisan ini disajikan secara deskriptif analitis dengan menggunakan 4 (empat) tahap penelitian yang lazim digunakan dalam penelitian sejarah pada umumnya.
\end{abstract}

Kata kunci: perkawinan politik, kekuasaan dan integrasi.

\begin{abstract}
After the Treaty of Bongaya in 1667, political marriage used as strategic to build power. This strategy is not new in the long history of South Sulawesi. Political Marriage has been done long ago by the Bugis-Makasar nobles. This strategy made the nobles succeed to instill power in other areas. However, political marriages, which occurred after the Treaty of Bongaya, were marriages that carried out by two kingdoms. The purpose of those marriages is to build extensive kinship and power. Political marriage does not just happen between two people from different family, but also done by two people from the same kinship. This strategy adopted because in Bugis-Makasar perspective, marriage means taking each other. Marriage does not just involve men and women who marry, but also involve relatives both sides with purpose to renew and strengthen their relationship. Through a political marriage, South Sulawesi can be unified. This research used historical method, which consist of four phases: heuristics, critics, interpretation, and historiography.
\end{abstract}

Keywords: political marriage, power, integration. 


\section{A. PENDAHULUAN}

Perkawinan memiliki makna yang sangat luas, meskipun pada intinya hanya menyatukan dua insan berbeda jenis dalam sebuah ikatan sah untuk hidup bersama, namun pada praktiknya tidaklah sesederhana itu. Di masa kini, di Indonesia kita melihat perkawinan antara putra Presiden Republik Indonesia, Edhie Baskoro Yudhoyono dan Siti Rubi Aliya Rajasa pada 24 Nopember 2011. Perkawinan ini diyakini oleh sebagian pengamat politik di Indonesia sebagai "perkawinan politik" antara Partai Demokrat dan Partai Amanat Nasional. Menurut beberapa pengamat, perkawinan ini bisa memperpanjang kekuasan SBY lewat anaknya. Banyak analis politik menyebut berbesan itu bakal mengerucut pada suksesi politik 2014. Hal ini tentu saja masih butuh penelitian lebih lanjut.

Pada masa orde baru, Presiden Soeharto juga melakukan hal yang sama yaitu mengawinkan putera-puterinya dengan pejabat penting. Siti Hediati alias Tatiek misalnya, menikah dengan Prabowo Subianto walaupun pada akhirnya keduanya bercerai. Prabowo yang saat itu Danjen Kopassus adalah anak Begawan ekonomi Soemitro Djojohadkoesoemo, yang pada masa awal orde baru menjabat posisi strategis, seperti menteri keuangan, menteri perindustrian, dan menristek. Pada masa itu nuansa politik terasa kental. Penguasa orde baru itu berupaya membangun dinasti politik mapan lewat perkawinan politik. Budaya semacam itu seakan melanggengkan patriarkhi, layaknya kaum ningrat masa lalu.

Dalam sejarah panjang Sulawesi Selatan, perkawinan yang dilandaskan pada kekuasaan sudah dikenal sejak terbentuknya kerajaan di wilayah ini. Terbentuknya kerajaan-kerajaan besar yaitu: Luwu, Bone, dan Gowa dengan raja pertamanya yang dikenal dengan istilah To-manurung, bertahan lewat perkawinan politik. To-manurung yang diyakini bukan manusia 'biasa' dikawinkan dengan seorang wanita dari kalangan manusia yang juga bukan manusia 'biasa'. Tomanurung tidak meminta untuk dikawinkan, tetapi "dipaksa" untuk kawin oleh orang dekatnya dengan tujuan untuk melanggengkan kekuasaan. Pada awalnya, pekawinan politik itu hanya terbatas dilakukan oleh kalangan bangsawan di pusat kekuasaan. Dalam perkembangan kemudian, perkawinan politik itu terjadi antara pusat dengan bangsawan lokal dalam kerajaan itu. Hal ini dilakukan untuk memperluas wilayah pengaruh dan kekuasaan penguasa di pusat kerajaan. Lambat laun perkawinan politik dilakukan pula antara penguasa-penguasa lokal di dalam kerajaan itu.

Anak yang lahir dari hasil perkawinan itu kelak akan dinobatkan menjadi pewaris tahta yang kelak menggantikannya. Demikianlah yang terjadi pada Kerajaan Luwu, Bone, dan Gowa. Raja-raja yang berkuasa di kerajaan itu adalah mereka yang memiliki garis keturunan langsung dari raja yang pertama.

Pada abad XVII, utamanya pasca Perjanjian Bungaya 1667, perkawinan politik yang terjadi, tidak lagi terbatas pada perkawinan bangsawan dari dalam kerajaan, tetapi juga terjadi antarkerajaan. Adalah Arung Palakka yang menjadi pelopor perkawinan antarkerajaan. Arung Palakka berambisi untuk membangun penyatuan antarkerajaan. Keinginan itu semakin bertambah ketika mengetahui bahwa kehadiran Belanda di Sulawesi Selatan, tidak seperti yang dibayangkan selama ini. Lewat Perjanjian Bungaya, Belanda telah memainkan peran yang sangat besar. Butir-butir perjanjian yang terdapat dalam Perjanjian Bungaya harus dipatuhi oleh setiap kerajaan. Butir-butir dalam perjanjian itu tidak saja berdampak politik, tetapi juga ekonomi dan sosial. Kerajaan-kerajaan yang ada di Sulawesi Selatan diadu domba antara satu dengan lainnya agar senantiasa muncul kekacauan. Dalam situasi demikian itu, kehadiran Belanda sangat diperlukan karena Belanda 
bertindak sebagai penengah dalam setiap kekacauan yang ada, seperti yang termuat dalam salah satu butir Perjanjian Bungaya.

Arung Palakka yang mencoba mengimbangi peran yang dimainkan oleh Belanda itu menjalankan satu strategi untuk membangun kekuatan. Kekuatan itu dibangun dengan memperluas wilayah pengaruh dan kekuasaannya. Salah satu jalan yang digunakan untuk memperluas wilayah pengaruh dan kekuasaannya itu adalah lewat perkawinan politik antarkerajaan. Perkawinan politik antara kerajaan terjadi secara luas sejak kehadiran Belanda lewat Perjanjian Bungaya pada tahun 1667. Pada waktu Belanda memutuskan untuk menguasai seluruh wilayah Sulawesi Selatan dalam satu pemerintahan di awal abad XX, politik adu domba yang dimainkan oleh Belanda tidak berhasil. Belanda harus menyatukan seluruh kekuataannya untuk menguasai wilayah ini. Perkawinan politik antarkerajaan yang sudah terbangun sejak abad XVII telah berhasil mendekatkan seluruh kerajaan yang ada di wilayah ini dalam satu keluarga besar.

Merujuk latar belakang di atas, masalah penelitian ini adalah bagaimana pekawinan politik yang terjadi di Sulawesi Selatan pada abad XVII. Untuk menguraikan pertanyaan pokok itu, ada beberapa hal yang perlu untuk mendapat perhatian lebih lanjut, yaitu:

1. Apakah alasan sehingga perkawinan politik dilakukan oleh para penguasa di Sulawesi Selatan pada abad XVIII?

2. Apakah dampak dari perkawinan politik yang dilakukan oleh para penguasa di Sulawesi Selatan pada abad XVIII?

Dari latar belakang penelitian di atas, dapat dirumuskan tujuan penelitian sebagai berikut:

a) Mengetahui alasan sehingga perkawinan politik dilakukan oleh para penguasa di Sulawesi Selatan pada abad XVIII

b) Mengetahui dampak dari perkawinan politik yang dilakukan oleh para penguasa di Sulawesi Selatan pada abad XVIII

c) Mengurai perkawinan politik yang terjadi di Sulawesi Selatan pada abad XVIII.

Ruang lingkup penelitian berguna untuk membatasi pembahasan pada pokok permasalahan. Ruang lingkup penelitian bertujuan untuk menegaskan batasanbatasan objek penelitian. Batasan-batasan yang dimaksud adalah ruang lingkup wilayah (spatialscope) dan ruang lingkup waktu (temporalscope). Hal ini dilakukan agar tidak terjadi kesimpangsiuran dan kerancuan dalam menginterpretasikan hasil penelitian. Menurut Taufik Abdullah, penentuan ruang lingkup yang terbatas dalam studi sejarah bukan saja menjadikannya lebih praktis dan mempunyai kemungkinan dikaji secara empiris, namun juga dapat dipertanggungjawabkan secara metodologis (Taufik Abdullah, 2005:10). Dalam tulisan ini lingkup spasialnya adalah Sulawesi Selatan. Sedangkan ruang lingkup temporal penelitian akan difokuskan kajian tulisan ini pada abad XVII dan XVIII. Pengambilan periode ini dilakukan karena Arung Palakka mulai men-setting perkawinan politik sejak abad XVII. Arung Palakka adalah motor penggerak dan penyebab terjadinya perkawinan politik pada masa itu.

Data yang dikumpulkan adalah data kualitatif yang diperoleh dengan cara studi pustaka. Tulisan ini, selain menggunakan sumber primer juga didukung oleh sumber sekunder. Sumber primer yang dimaksud berupa dokumen-dokumen asing dan juga historiografi tradisional Bugis-Makassar (lontarak). Sumber sekunder berupa bukubuku, makalah, dan juga makalah-makalah yang mempunyai keterkaitan dengan penelitian.

\section{B. METODE PENELITIAN}

Tulisan ini disajikan secara deskriptif analitis dengan menggunakan 4 tahap penelitian yang lazim digunakan dalam penelitian sejarah pada umumnya. 
Empat tahap penelitian ini merupakan suatu bagian yang saling berurutan dan saling berkaitan satu dengan yang lain. Tahapan penelitian tersebut adalah pengumpulan sumber (heuristik), kritik data atau sumber, interpretasi dan historiografi.

\section{HASIL DAN BAHASAN}

\section{1) Kondisi Politik Kerajaan Gowa dan Bone Abad XVII}

Abad XVII ditandai dengan banyak peristiwa sejarah. Perjalanan sejarah di abad ini didominasi oleh kekuasaan Kerajaan Gowa yang begitu besar. Pada awal abad ini diwarnai dengan upaya yang dilakukan oleh Kerajaan Gowa untuk menyebarkan agama Islam di Sulawesi Selatan, namun 3 (tiga) kekuasaan Bugis yang tergabung dalam persekutuan Tellumpoccoe, yaitu Bone, Wajo dan Soppeng mencoba menghalangi upaya Kerajaan Gowa tersebut. Hal ini disebabkan ada kecurigaan bahwa upaya tersebut tidak murni untuk menyebarkan agama Islam tapi juga adalah upaya untuk memperluas wilayah kekuasaan dan pengaruh Kerajaan Gowa sehingga kemudian menimbulkan perang antara Kerajaan Gowa terhadap 3 kekuasaan Bugis. Seiring dengan peristiwa itu juga akhirnya Kerajaan Bone kemudian dijadikan daerah taklukan Kerajaan Gowa.

Perserikatan Dagang Belanda (VOC) itu masuk Sulawesi tahun 1607. Awalnya para pelaut VOC berperilaku sama dengan pelaut-pelaut yang lain. Namun kemudian VOC sebagai suatu perusahaan dagang dalam setiap usahanya ingin mendapatkan keuntungan sebanyakbanyaknya. Dalam usahanya membangun wilayah kekuasaan ekonomi, VOC berusaha untuk menguasai perdagangan dengan jalan monopoli. Usaha itu pada beberapa kerajaan dapat ia wujudkan, namun untuk kerajaan lainnya mendapat tantangan. Salah satu kerajaan yang menolak keinginan VOC untuk melakukan monopoli perdagangan adalah Kerajaan Gowa. Untuk itu, Kerajaan Gowa berusaha mempertahankan perairan Makassar dengan cara meminta To Bala, Jennang pada masa Kerajaan Bone di bawah taklukan Kerajaan Gowa untuk mengerahkan 10.000 orang untuk dijadikan pekerja. Tenaga ini tidak hanya berasal dari rakyat biasa atau budak, namun juga dari kalangan bangsawan. Di sinilah, bangsawan Bone mulai bangkit untuk melawan Kerajaan Gowa termasuk Arung Palakka yang melarikan diri sampai ke Buton dan kemudian menumpang kapal Belanda menuju Batavia untuk mencari bantuan.

VOC melakukan beberapa usaha untuk mewujudkan keinginannya memonopoli perdagangan termasuk untuk itu VOC harus menaklukkan Gowa, namun gagal. Usaha itu baru dapat diwujudkan ketika Arung Palakka, raja di Kerajaan Bone datang menawarkan kerjasama menaklukkan Gowa. Tawaran ini disambut baik oleh Gubernur Jenderal Joan Maetsueyker. VOC melihat bahwa apa yang diinginkan oleh Arung Palakka itu dapat dijadikan alasan untuk melakukan serangan atas Gowa. Kerajaan Gowa adalah ancaman nyata bagi VOC dalam mewujudkan cita-cita VOC memonopoli perdagangan di wilayah kepulauan rempah-rempah. Akhirnya, pecah perang besar yang dikenal dengan perang Makassar yang mengakhiri kebesaran Kerajaan Gowa.

Sebelum perang Makassar, Maetsuyker meminta Arung Palakka dan prajurit-prajuritnya untuk membantu VOC menyelesaikan permasalahan yang dihadapi oleh VOC di Sumatera Barat. Arung Palakka sangat populer sebab berhasil menaklukkan Sumatra dan membumihanguskan perlawanan rakyat Minangkabau terhadap VOC.

Arung Palakka menyimpan dua sisi diametral. Di satu sisi hendak membebaskan Bugis, namun di sisi lain justru menaklukkan daerah lain di Nusantara. Kisahnya berawal pada tahun 1662, dibuat perjanjian antara VOC dengan pemimpin Minangkabau di 
Padang. Perjanjian yang kemudian di sebut Perjanjian Painan itu bertujuan untuk monopoli dagang di pesisir Sumatera, termasuk monopoli emas Salido. Sayang, rakyat Minang mengamuk pada tahun 1666 dan menewaskan perwakilan VOC di Padang bernama Jacob Gruys. Arung Palakka kemudian dikirim ke sana dalam ekspedisi yang dinamakan Ekspedisi Verspreet. Bersama pasukan Bugis, ia berhasil meredam dan mematikan perlawanan rakyat Minangkabau hingga menaklukkan seluruh pantai barat Sumatera, termasuk memutus hubungan Minangkabau dengan Aceh. Kekuasaan VOC diperluas hingga Ulakan di Pariaman. Di tempat inilah, Arung Palakka diangkat sebagai Raja Ulakan. Bukti sejarah bahwa Arung Palakka memerangi dan mengalahkan Pariaman adalah payung atribut kerajaan itu masih ada, sekarang tersimpan di Bone.

Tugas yang dibebankan di atas pundak Arung Palakka diselesaikan dengan baik. Atas jasa itu ia mendapat penghargaan dari VOC. Arung Palakka dan Joan Maetsuyker menandatangani perjanjian persahabatan yang isinya "Selama matahari dan bulan memancarkan sinarnya, selama itu Bone dan Kompeni Belanda tetap bersatu teguh, pintu kekuatan dan tangan kita tetap teguh". Sepulang dari Pariaman, Arung Palakka bersama dengan VOC memerangi Kerajaan Gowa. Perang yang lebih dikenal dengan Perang Makassar tersebut berlangsung dari Desember 1966 sampai 18 November 1967. Makassar berhasil diduduki dan akhirnya Kerajaan Gowa terpaksa menandatangani perjanjian Bungaya. Dengan ditandatangani perjanjian Bungaya tersebut, Kerajaan Bone menjadi Negara merdeka kembali.

Hubungan Kerajaan Bone dan VOC ini tetap terjalin sepanjang abad XVII ini. Selain membantu VOC di Pariaman, Arung Palakka juga membantu menumpas pemberontakan yang dilakukan Trunojoyo di Jawa Timur. Hubungan yang dibangun antara Arung Palakka dan VOC dalam perjalanan panjang sejarah Sulawesi Selatan tidak selamanya berjalan mulus. Dalam banyak hal hubungan itu kadang kala menunjukkan ketidakharmonisan karena keduanya memiliki sudut pandang yang berlainan bagaimana memanfaatkan daerah ini. Perhatian besar yang diberikan pada soal ekonomi oleh VOC kadang tidak sesuai dengan keinginan Arung Palakka. Meskipun demikian Kerajaan Bone mendapat banyak keuntungan dalam hubungan ini.

Setelah Kerajaan Gowa dapat ditaklukkan dan demikian pula sekutusekutunya, Kerajaan Bone menjadi satusatunya kerajaan yang terkuat di daerah ini dan tumbuh menjadi kerajaan yang dipertuan oleh semua Raja Bugis. Meskipun kompeni tidak pernah mengakui secara resmi kekuasaan Bone atas kerajaan di Sulawesi Selatan itu, tetapi hubungan kompeni dengan kerajaan-kerajaan lain selalu dengan perantara Kerajaan Bone. Akibat sikap kompeni itu, Kerajaan Bone tumbuh menjadi kerajaan paling berperangaruh di Sulawesi Selatan.

Hubungan akrab itu tidak selalu berjalan mulus. Selain intrik-intrik politik yang masih tetap berlangsung, Kerajaan Bone dalam perkembangannya kemudian mencoba mengambil alih peran yang pernah dimainkan oleh Kerajaan Gowa. Usaha itu dapat berjalan dengan baik karena adanya VOC yang siap membantunya dalam situasi yang bagaimanapun.

Arung Palakka yang kemudian diangkat menjadi raja Bone menggantikan La Maddaremmang, dalam banyak hal tidak dapat dengan leluasa menjalankan kekuasaannya. Ia tunduk pada isi Perjanjian Bungaya 1667. Arung Palakka bagaikan robot yang harus selalu mengikuti apa yang diinginkan oleh VOC. Semua ini disebabkan hutang budi yang telah diterimanya ketika Speelman membantunya untuk melepaskan Kerajaan Bone dan Soppeng dalam genggaman Kerajaan Gowa. 
Dalam perkembangannya kemudian, Arung Palakka melihat bahwa kehadiran VOC tidak menyelesaikan persoalan yang terjadi di Sulawesi Selatan. VOC hanya memperalat Arung Palakka untuk mengatasi persoalan politik yang terjadi di wilayah ini. Tugas Arung Palakka tampaknya semakin sulit karena VOC cenderung membiarkan persoalan politik tetap mengambang tanpa penyelesaian. VOC menginginkan keadaan politik di wilayah ini tetap terpecah belah antara Bugis dan Makassar. Hal ini berarti tugas yang diemban oleh Arung Palakka semakin rumit. Oleh karena itu, Arung Palakka berusaha menjalankan satu strategi dalam usahanya mempersatukan kerajaankerajaan yang ada di wilayah ini. Lewat kemenakannya, La Patau Matanna Tikka, Arung Palakka memulai membangun kekuasaan lewat perkawinan.

\section{2) Perkawinan Politik dan Kekuasaan}

Usaha Arung Palakka untuk menyatukan kerajaan-kerajaan yang ada di Sulawesi Selatan, tidak mudah diwujudkan mengingat kekalahan Kerajaan Gowa tidak serta merta membuat sekutu Gowa menerima kekalahan itu. Hubungan antara VOC dan Arung Palakka pun tidak selalu berjalan mulus, karena keduanya memiliki kepentingan yang berbeda. Usaha Arung Palakka tampaknya mengalami kendala besar selama persoalan politik di Sulawesi Selatan dibiarkan mengambang tanpa penyelesaian. Selama ini VOC cenderung membiarkan persoalan politik berjalan apa adanya. Kerajaan-kerajaan dibiarkan menjalankan pemerintahannya, namun harus tetap berada dalam koridor Perjanjian Bungaya. Butir-butir yang terkandung dalam Perjanjian Bungaya itu, baik langsung maupun tidak langsung mengebiri seluruh kerajaan yang ada, termasuk juga Kerajaan Bone. Kerajaankerajaan yang ada di wilayah ini saling curiga, dan hal ini tentu saja menambah kuat peran VOC. ${ }^{1}$

Keterlibatan VOC dalam persoalan intern kerajaan-kerajaan yang ada di daerah ini mulai disikapi oleh Arung Palakka. Setelah berhasil menempatkan Sultan Abdul Jalil di atas tahta Kerajaan Gowa pada tahun 1677, lambat laun keadaan politik di Sulawesi Selatan mulai kondusif. Selain itu, Arung Palakka yang sukses menyelesaikan persoalan Trunojoyo dan Karaeng Galesong di Jawa Timur, mulai merasa 'bebas' dari belenggu hutang 'nyawanya' selama ini. ${ }^{2}$ Arung Palakka, dalam banyak hal tidak dapat bertindak bebas dalam menyikapi setiap persoalan yang ada di daerah ini, tanpa terlebih dahulu mendapat petunjuk dan persetujuan dari VOC. Sebagai orang Bugis, ia merasa sangat berutang budi atas bantuan Speelman yang membantunya membebaskan Kerajaan Bone dari kekuasaan Kerajaan Gowa. Hutang budi itulah yang membuatnya seperti robot dalam menjalankan kekuasaannya di Sulawesi Selatan. Akan tetapi, setelah berhasil menyelesaikan persoalan Trunojoya dan Karaeng Galesong atas permintaan Speelman, Arung Palakka mulai 'berani' bersikap jika ada hal-hal yang kurang disenanginya.

Langkah awal yang dilakukan oleh Arung Palakka dalam usahanya membangun kesatuan di wilayah ini adalah lewat perkawinan. Selama ini perkawinan menjadi senjata ampuh yang dilakukan oleh kelompok istana dalam membangun kekuatan. Perkawinan dilakukan tidak saja antara putra atau putri bangsawan dengan penguasa-penguasa lokal yang tidak

\footnotetext{
${ }^{1}$ Salah satu isi Perjanjian Bungaya adalah menempatkan VOC sebagai penengah dalam setiap persoalan yang muncul di daerah ini.

${ }^{2}$ Speelman telah memberi bantuan kepada Arung Palakka dalam membebaskan Kerajaan Bone dan Soppeng pada tahun 1667. Selama kurang lebih 17 tahun lamanya Kerajaan Bone dan Soppeng berada di bawah kekuasaan Gowa.
} 
memiliki hubungan darah, tetapi perkawinan juga dilakukan antarsepupu, baik sepupu satu kali, dua kali dan tiga kali. Hal ini dilakukan demi mempertahankan kemurnian darah, hal yang sangat penting untuk menduduki tahta pemerintahan.

Pada masa Arung Palakka, perkawinan yang terjadi tidak terbatas hanya di dalam kerajaan, tetapi juga dikembangkan di luar kerajaan. Perkawinan antarkerajaan yang tidak memiliki hubungan darah merupakan hal baru yang dilakukan oleh Arung Palakka. Perkawinan antarkerajaan dipandang sebagai satu langkah untuk mendekatkan satu kerajaan dengan kerajaan lainnya.

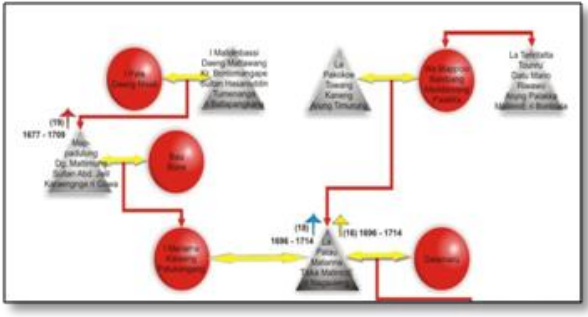

Gambar 1. Hubungan Kekerabatan antara Kerajaan Bone dengan Gowa.

Sumber: Dibuat berdasarkan Lontarak Bone dan berbagai lontarak lainnya.

Usaha Arung Palakka untuk membangun kesatuan dan persatuan di wilayah ini adalah dengan mengawinkan La Patau dengan putri penguasa Kerajaan Gowa ketika itu, ${ }^{3}$ Sultan Abdul Jalil. Pernikahan itu dilaksanakan sewaktu Arung Palakka memegang tampuk kekuasaan di Kerajaan Bone. ${ }^{4}$

${ }^{3}$ La Patau adalah anak dari saudara Arung Palakka. La Patau diproklamirkan sebagai pewaris tahta Kerajaan Bone tidak lama setelah Arung Palakka kembali dari Jawa setelah menyelesaikan tugasnya memadamkan perlawanan Karaeng Galesong.

${ }^{4}$ Arung Palakka sendiri yang datang melamar dan membuat syarat agar anak pertama yang lahir dari pernikahan itu dinobatkan menjadi raja di kerajaan ibunya. Usaha yang dirintis oleh Arung Palakka itu, adalah sesuatu yang

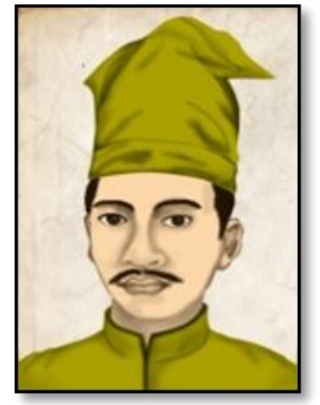

Gambar 2. Sultan Abdul Jalil, raja Gowa ke-19.

Sumber: Koleksi Yayasan Mappatuju, Makassar.

Sadar akan dendam yang pasti belum hilang, Arung Palakka melamar cucu mantan Raja Gowa, Sultan Hasanuddin yang bernama We Mariama. Ia adalah putri Raja Gowa Sultan Abdul Jalil, anak Sultan Hasanuddin raja Kerajaan Gowa dan merupakan seteru Arung Palakka (Lontarak Akkarungeng ri Bone).

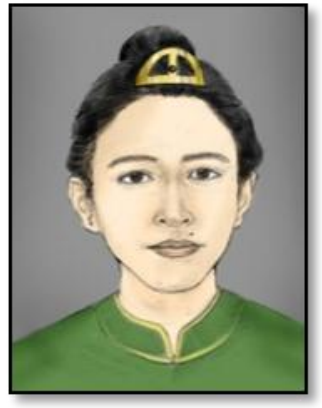

Gambar 3. I Mariama Karaeng Pattukangang istri La Patau dari Kerajaan Gowa.

Sumber: Koleksi Yayasan Mappatuju, Makassar

Arung Palakka menyadari bahwa masih banyak bangsawan tinggi Kerajaan Gowa yang belum bisa menerima

baru dan belum pernah terjadi sebelumnya. Inilah kali pertama dalam sejarah Sulawesi Selatan, pernikahan antara elite bangsawan antarkerajaan yang mendakwa sama-sama keturunan dari To-manurung. 
kehancuran Gowa. ${ }^{5}$ Lewat perkawinan ini Arung Palakka dapat berharap permusuhan yang terjadi selama ini akan berangsurangsur hilang. Ambisi Arung Palakka itu ditunjukkan dengan sungguh-sungguh. Ia sendiri yang mengetuai delegasi dalam pelamaran (Lontarak Akkarungeng Bone). Ia tidak ingin lamaran itu ditolak. Sebagai penguasa tunggal di Sulawesi Selatan ketika itu, pengaruh dan wibawanya sangat tinggi, tidak ada seorang raja pun yang berani menolak kehendaknya.

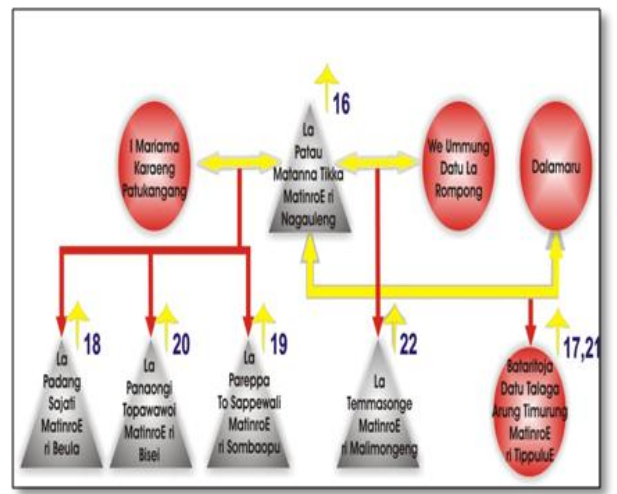

Gambar 4. Perkawinan Politik antara Kerajaan Bone dengan Luwu dan Gowa.

Sumber: Dibuat berdasarkan Lontarak Bone dan berbagai sumber lontarak lainnya.

Pada waktu pelamaran itu, Arung Palakka juga telah memasukkan salah satu syarat dalam pelamaran itu, yaitu anak pertama dari pernikahan itu dijadikan raja di kerajaan ibunya (Lontarak Akkarungeng Bone). Hal itu dilakukan untuk memastikan bahwa anak-anak bangsawan dari Bone dapat bertahta di Kerajaan Gowa. Jika hal ini terwujud berarti keturunan mereka kelak akan juga dapat menguasai kedua kerajaan tersebut.

\footnotetext{
${ }^{5}$ Demikian besar dan kuatnya Kerajaan Gowa di abad XVII, sehingga banyak orang yang tidak percaya bahwa Kerajaan Gowa dapat ditaklukkan oleh Kerajaan Bone yang memanfaatkan kekuatan VOC ketika itu. Untuk keterangan lanjut baca L.Y. Andaya.
}

Arung Palakka juga melamar putri bangsawan dari Kerajaan Luwu ${ }^{6}$, yaitu We Ummung Opu Larompong untuk kemenakannya, La Patau. Arung Palakka yang memiliki pengalaman hidup yang sangat luas tahu benar siapakah yang harus mendampingi kemenakannya itu. Pilihan jatuh pada putri bangsawan dari Kerajaan Luwu, pewaris Epos La Galigo, dengan darah Kerajaan Bone, pewaris darah Tomanurung. Pernikahan keduanya membuahkan seorang anak yang bernama Batari Toja. Ia kemudian diangkat menjadi raja di Luwu menggantikan neneknya. Sebelumnya, Batari Toja diangkat pula menjadi raja di Kerajaan Bone setelah La Patau wafat pada tahun 1728, dan juga di Kerajaan Soppeng.

Perkawinan ini merupakan jalan perdana yang diciptakan oleh Arung Palakka agar bangsawan Bone tidak saja besar ke dalam dengan melakukan kawin mawin di antara sepupu, tetapi juga keluar melintasi batas geografis wilayah Kerajaan Bone. Oleh karena darah menjadi ukuran penting maka yang dapat dinikahi oleh seorang bangsawan tinggi Bone adalah mereka yang memiliki status yang sama. Demikian pentingnya darah untuk tetap dijaga, maka seorang raja selalu saja melakukan pernikahan ketika ia berkuasa. Ada kepercayaan yang menyebar di kalangan para bangsawan bahwa anak yang lahir ketika orang tuanya berkuasa memiliki kualitas darah yang lebih sempurna (Mappangara, 2010: 233).

Istri La Patau lainnya adalah Dala Maru. Dari pernikahannya lahir dua orang anak laki-laki yang bernama La Temmasonge' dan La Wattaeng. La Temmasongeng diangkat menjadi raja menggantikan saudara tirinya, Batari Toja.

\footnotetext{
${ }^{6}$ Meskipun ketika itu kebesaran nama Luwu sudah mulai memudar, namun Luwu masih tetap merupakan kerajaan yang relatif berpengaruh dan dukungannya masih dibutuhkan oleh siapa saja yang bermaksud mengincar kedudukan sebagai penguasa tertinggi di Sulawesi Selatan.
} 
Sebelum diangkat menjadi raja Bone, ia menjabat jabatan sebagai Panglima Perang Kerajaan Bone.

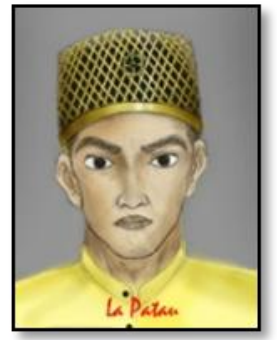

Gambar 5. La Patau, raja Bone ke-16. Sumber: Koleksi Yayasan Mappatuju, Makassar.

Pernikahan antara La Patau dengan putri bangsawan Kerajaan Gowa, I Mariama Karaeng Pattukangang menghasilkan tiga orang anak. La Pareppa, ${ }^{7}$. La Padassajati, dan La Panaongi. La Pareppa, anak pertama yang lahir dari pernikahan ini kemudian dinobatkan menjadi raja di Kerajaan Gowa sebagai raja yang ke-20 menggantikan mertuanya. ${ }^{8}$ Ia berkuasa selama dua tahun. Ia menikah dua kali, pertama dengan Siti Rahima Karaeng Pabinneyang pada tanggal 16 Mei 1702. Ia adalah anak perempuan bungsu Karaeng Kanjilo, Sultan Tallo dan Karaeng Parang-Parang, anak dari Karaeng Bisei, Sultan Gowa. Menikah untuk kali kedua dengan Siti Habiba (Gumitri) pada tanggal 2 Desember 1706, anak Syekh Yusuf dari istrinya yang bernama Kare Kontu.

\footnotetext{
${ }^{7}$ Dalam sejarah Kerajaan Gowa ia lebih dikenal dengan julukan Karaeng Anak Moncong. Lihat Lontarak Bilang Raja Gowa dan Tallok (naskah Makassar).

${ }^{8}$ Ia juga diangkat menjadi raja di Kerajaan Bone pada tahun 1720-1721; dan di Kerajaan Soppeng sebagai Raja Soppeng ke-20 pada tahun 1721-1722).
}

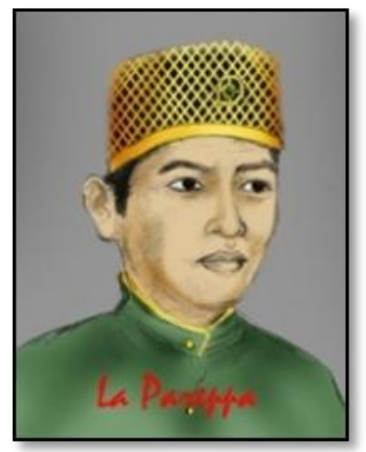

Gambar 6. La Pareppa To Sappewali Raja Gowa ke-21 dan raja Bone ke18.

Sumber: Koleksi Yayasan Mappatuju, Makassar.

Dari pernikahannya ini ia menghasilkan satu orang anak laki-laki yang bernama I Massanglomo. Ia pernah menjabat sebagai Panglima Perang di Kerajaan Bone dan juga diangkat menjadi Arung di Sumaling. ${ }^{9}$ Anak perempuannya bernama Siti Zaenab Karaeng Patukangang. Ia menikah sebagai istri kedua dengan I Manrabia Karaeng Kanjillo, Sultan Kerajaan Tallo. Anak perempuan keduanya bernama I Taniaja Maning Ratu Siti Amira, lahir dari istri pertamanya yang bernama Siti Rahima. Ia menikah dengan I Mappainga Karaeng Limpangang, Sultan Tallo. ${ }^{10}$

La Temmasongeng dikenal sebagai seorang raja yang memiliki banyak istri (Padindang, 2007:12). Dua orang istrinya yang dianggap sebagai permaisurinya adalah Siti Aisyah dan Siti Habibah, keduanya kakak beradik. Pernikahannya dengan Siti Aisyah melahirkan beberapa orang anak, di antaranya La Baloso. Ia menikah dengan sepupu satu kalinya yang

${ }^{9}$ Ia menikah dengan Petta Tajung dan memiliki dua orang anak. Anak pertama bernama Arung Sumalieng dan Abdul Rahman, Karaeng Bisei.

${ }^{10}$ Dari pernikahan itu lahir 4 orang anak, dua laki-laki dan dua perempuan. Anak laki-lakinya bernama I Mallawangngau Mansur Syah yang kemudian menjadi Raja di Gowa. Seorang lagi anaknya yang bernama I Mappaba'basa Sultan Abdul Qudus, menjadi Raja di Gowa. 
bernama We Tenriawaru, dari pernikahan ini lahirlah $\mathrm{La}$ Sibengngareng yang kemudian pernah diangkat menjadi Maddanreng di Kerajaan Bone.

Pada tahun 1799 VOC dinyatakan bangkrut dan seluruh wilayah kekuasannya diambil alih Pemerintah Belanda. Seiring dengan kejatuhan itu Kerajaan Bone mulai mengembangkan pengaruh dan kekuasaannya setelah kurang lebih 65 tahun berhasil mempertahankan kerajaan Bone dari gangguan pihak luar. Elite bangsawan Bone mulai bangkit untuk membangun persatuan dan kesatuan di seluruh Sulawesi Selatan dan siap berdiri di barisan depan dalam menentang bangsa asing yang ingin merongrong kewibawaan bukan saja Kerajaan Bone, tetapi juga kerajaan-kerajaan yang bersahabat dengan Bone.

Jaringan bangsawan Bone mulai masuk ke Kerajaan Suppa pada waktu La Kuneng menduduki tahta kerajaan. Ia adalah anak La Raga arung Alitta, ${ }^{11}$ dan memiliki beberapa orang istri, namun dalam catatan lontarak hanya dua orang istri yang disebut. Istri pertama bernama We Tenri Arung Singkang, putri dari La Maddukelleng. Pernikahannya ini menghasilkan seorang anak bernama $\mathrm{La}$ Pabeyangi yang dikenal dengan gelar Cella' Belawa. Istri kedua Lakuneng adalah anak La Ballosong To Akkato, penguasa di Kerajaan Bone dengan istrinya yang bernama We Tenriawaru Arung Lempang. La Ballosong adalah anak La Temmasonge, Raja Bone yang ke-16 dari istrinya yang bernama I Momong Siti Aisyah (Lontarak Silsilah Kerajaan Suppa Hubungannya dengan Kerajaan Tellu Boccoe)

Pernikahan antara La Kuneng dengan We Tenridellu menghasilkan 5 orang anak. Dari lima orang anaknya, empat orang memegang jabatan penting di daerah Ajjatappareng, yaitu We Timeng seorang perempuan yang menjadi

${ }^{11}$ Ia bersaudara kandung dengan La Sangka, Datu di Suppa.
Addatuwang di Sawitto, We Cinde juga menjadi Addatuwang di Sawitto, La Tenrilengka (laki-laki) menjadi Datu di Suppa dan La Cibu (laki-laki) menjadi Addatuwang di Sawito. Seorang lagi anaknya perempuan yang bernama We Maddika tidak memegang jabatan penting namun ia menikah dengan La Tenrisukki Arung Kajuara sepupu satu kalinya. Dari pernikahan itu lahir seorang anak perempuan yang bernama We Tenriawaru Pancai Tanah Besse Kajuwara, yang kemudian menduduki jabatan sebagai raja di Kerajaan Bone.

We Tenriawaru Pancai Tanah Besse Kajuara menikah dengan sepupu satu kalinya yang bernama La Parenrengi Arung Pugi. Pernikahannya menghasilkan empat orang anak. Tiga dari empat orang anaknya kemudian diangkat menjadi penguasa di Alitta, Suppa dan di Ogi.

Setelah La Kuneng wafat ia digantikan oleh anaknya yang bernama La Tenri Lengka sebagai Datu Suppa yang ke$18 .^{12}$ Pada masa pemerintahannya terjadi perang dengan Addatuwang Sidenreng yang bernama La Wawo. Tabiat La Wawo sering mengusik kedaulatan tetangganya dan mendatangkan bantuan dari luar untuk menyerang Suppa. Addatuwang Sidenreng berambisi untuk menguasai Ajjatappareng dan mewariskannya kepada anak-cucunya, namun hal itu ditentang oleh Batari Toja, Raja Bone yang telah mewariskan tahta Datu Suppa, Addatuwang di Sawitto dan Arung di Alitta.

Perselisihan yang terjadi antara Addatuwang Sindenreng dengan Datu Suppa diketahui oleh Belanda. VOC yang sering mencari celah untuk melibatkan diri dalam setiap pertentangan yang muncul memanfaatkan keadaan tersebut. VOC cenderung membantu pihak yang lemah agar ia dapat memperoleh kompensasi yang besar dan menguntungkan

\footnotetext{
${ }^{12}$ Dalam catatan Lontarak diketahui bahwa ia tidak memiliki istri yang sederajat dengannya, sehingga tidak ada anaknya yang bisa menggantikan kedudukannya.
} 
sehubungan dengan bantuannya kelak jika memenangkan perang. Dalam perang itu VOC bersama beberapa pasukannya orang Ambon dan Ternate menyerang Suppa dari laut, sedangkan Addatuwang Sidenreng menyerang dari arah darat. Perang itu akhirnya dimenangkan oleh Sidenreng. Akibat kekalahan itu Kerajaan Suppa kehilangan sebagian wilayahnya yang diambil oleh Sidenreng yang kemudian dimanfaatkan oleh VOC. Salah satu wilayah yang dimanfaatkan oleh VOC adalah daerah Pare-Pare. VOC beranggapan bahwa jatuhnya Pare-Pare banyak disebabkan andil dari VOC, meskipun diserahkan kepada Addatuwang Sidenreng namun itu dipinjamkan oleh VOC. $^{13}$

Setelah Besse Kajuara kalah dalam perang melawan Belanda ia terpaksa mengungsi. Pertama ia ke daerah Passempe, satu wilayah dalam kekuasaan Bone yang dipandang pendukung kuat kerajaan. Namun ia kemudian akhirnya harus mengungsi dan tiba di daerah Ajjatappareng. Karena pada waktu itu Datu Suppa tidak mempunyai seorang anakpun yang layak menggantikan kedudukannya karena istrinya tidak sederajat dengannya, akhirnya Besse Kajuara dinobatkan menjadi Datu di Suppa ke-29.

Setelah Besse Kajuara wafat ia digantikan oleh anaknya yang bernama We Bubeng. Ia menikah dengan La Rumpa Datu Patiro namun tidak memiliki anak sampai ia bercerai. Akhirnya We Bubeng mempersiapkan kemanakannya untuk menjadi Datu di Suppa yang bernama La Tenrisukki Mappanyukki gelar Sultan Ibrahim yang menjadi Datu di Suppa yang ke-31 (Lontarak Kerajaan Tanete dan Hubungannya dengan Kerajaan Tellum

\footnotetext{
${ }^{13}$ Lontarak Kerajaan Tanete dan Hubungannya dengan Kerajaan Tellu Boccoe. Addatuang disuruh menagih pajak setiap perahu yang masuk membawa barang, karena Pare-Pare merupakan pelabuhan perahu kapal yang berbobot besar.
}

Boccoe).${ }^{14}$ Pada waktu Belanda menyerang Kerajaan Gowa La Tenrisukki Mappanyukki melibatkan diri dan akhirnya ia ditangkap dan dibuang ke Selayar.

Hubungan kekerabatan antara Kerajaan Bone dan Soppeng telah dimulai pada masa pemerintahan raja Soppeng ke11, Datu La Mataesso. Pada masa pemerintahannya terjadi perselisihan antara Kerajaan Soppeng ri Aja dan Soppeng $\mathrm{Ri}$ Lau. Penyebab terjadinya perselisihan tidak diketahui dengan pasti, namun sehubungan dengan perselisihan itu, Kerajaan Soppeng ri Lau merasa tidak berdaya dan malu (siri') dengan yang menimpa kerajaannya. Oleh karena itu ia mencari bantuan untuk menegakkan sirinya. Datu La Makkarodda memutuskan untuk mencari bantuan ke Kerajaan Bone. Setelah sekian lama berada di Bone dan tidak juga mendapat kepastian tentang bantuan yang sangat diharapkannya, La Makkarodda melamar dan menikahi We Tenripakkuwa, adik raja Bone yang sedang berkuasa, La Tenrirawe Bongkae. Pernikahan ini telah menaikkan gengsi dan wibawa La Makkarodda di mata musuhnya, La Mataesso. Mendengar La Makkarodda menikah dengan adik raja Bone, La Mataesso mengirim utusan ke Bone untuk membujuk La Makarodda kembali menjadi raja Kerajaan Soppeng ri Lau. La Mataesso khawatir bahwa La Makkaroddang akan meminta bantuan kepada Kerajaan Bone untuk memulihkan kembali kekuasaannya di Soppeng. Sebelum hal itu terjadi La Mataesso dengan segala upaya melakukan perdamaian dengan La Makkarodda. Salah satu yang dilakukannya adalah dengan melakukan perundingan di Bone. Usaha perdamaian yang dilakukan oleh $\mathrm{La}$ Makkarodda dan juga La Mataesso akhirnya menciptakan satu kerajaan yang dikenal dengan nama Kerajaan Soppeng.

\footnotetext{
${ }^{14}$ Pada masa beliau berkuasa kerajaan-kerajaan yang termasuk Lima Ajjateppareng, yaitu Suppa, Alitta, Sidenreng, Sawitto, dan Rappang.
} 
Terlepas dari perselisihan yang sering muncul sebelum Arung Palakka berkuasa, Kerajaan Soppeng dan Bone memiliki sejarah yang panjang. Pada waktu Arung Palakka mengadakan perlawanan melawan Gowa, ia malah mendapat bekal dari raja Soppeng yang bernama La Tenribali $^{15}$ (Leonard Y. Andaya: 2004, 72-73).

Pengaruh besar yang ditanamkan Bone pada Kerajaan Soppeng bermula setelah kemenangan Arung Palakka bersama VOC mengalahkan Kerajaan Gowa. La Patau diangkat menjadi raja di Soppeng sebagai raja ke-18 (1696-1714). Dalam pemerintahan selanjutnya anak $\mathrm{La}$ Patau dari istrinya I Mariama, putri bangsawan dari Gowa dan juga I Mummu, putri bangsawan dari Luwu semuanya menjadi raja di Kerajaan Soppeng yaitu menjadi raja ke-19, 20, 21, 22, dan $24{ }^{16}$

Setelah raja Soppeng yang ke-24, Batari Toja wafat ia digantikan oleh saudara tirinya La Temmasonge' sebagai raja ke-25. Raja-raja berikutnya dikuasai pula oleh keturunan La Temmasonge' sampai pada raja yang ke-27. Raja yang ke-29 yang dikenal dengan nama Abdul Gani adalah satu-satunya raja yang dapat menyusup menggantikan keturunan La Temmasonge'. Ia adalah seorang calabai (wadam) dan dapat menduduki raja karena pengaruh Matthes, dan juga ketika itu peran dari bissu sangat besar. Setelah wafat raja-raja Soppeng kembali dipegang

\footnotetext{
${ }^{15}$ La Tenribali adalah raja di Kerajaan Soppeng. Sebelum Arung Palakka bersama dengan Arung Bila, Arung Apanang dan Datu Citta berangkat meninggalkan Sulawesi Selatan untuk mencari bantuan untuk membebaskan Kerajaan Soppeng dan Bone, Arung Palakka bertemu dengan La Tenribali dan menyampaikan keinginannya itu. La Tenribali memberikan 100 kati atau sekitar $60 \mathrm{~kg}$ emas sebagai bekalnya.

${ }^{16}$ Raja Soppeng yang ke 23 dipegang oleh La Oddang Riu. Orang tuanya adalah Larumpang Mega, Addatuang Suppa.
}

oleh keluarga keturunan La Temmasonge' sampai raja yang terakhir.

\section{PENUTUP}

Selama ini istilah Tellu Cappa' (Tiga Ujung: ujung badik, lidah, dan ujung kemaluan) seolah-olah menjadi simbol bagi orang Bugis-Makassar dalam menanamkan pengaruh dan kekuasaannya. Hal ini tidaklah sepenuhnya benar. Penelitian ini menunjukkan bahwa lewat jalan perkawinanlah (ujung kemaluan) yang menjadi pilihan utama bagi orang Bugis-Makassar dalam mempertahankan pengaruh dan kekuasaannya. Perkawinan pulalah yang menjadikan pengaruh dan kekuasaan orang Bugis-Makassar dapat bertahan lama, seperti yang terjadi di Johor, Selangor, Riau, Aceh,dan beberapa wilayah lainnya. Bagi orang BugisMakassar, perkawinan bukanlah sekadar bersatunya dua insan yang berlainan jenis, namun penyatuan dua keluarga dalam satu ikatan yang lebih luas. Bagi orang Bugis-Makassar, tidak ada larangan bagi perkawinan sepupu satu kali, dua kali, maupun tiga kali, untuk menuju tangga kekuasaan. Bahkan perkawinan antara paman dan keponakan bisa saja terjadi demi membangun pengaruh dan kekuasaan.

Perkawinan politik antara kerajaan yang dibangun lebih intens dimasa Arung Palakka telah menjadikan wilayah ini berada dalam satu ikatan kekerabatan yang menjadikan darah sebagai simbol penyatuan. Pelan tapi pasti, strategi ini telah menjadikan hubungan antara kerajaan-kerajaan yang ada di Sulawesi Selatan semakin akrab dan tidak mudah diadu domba oleh penjajah. Ikatan kekerabatan itu menjadi satu kekuatan yang menjadi modal besar dalam membangun perlawanan melawan penjajah. Ikatan kekerabatan itu pulalah yang membuat Belanda bertindak sangat kejam dalam membangun pengaruh dan kekuasaannya di wilayah ini. 


\section{DAFTAR SUMBER}

\section{Manuskrip}

Lontarak Akkarungnge Bone (Koleksi Museum La Pawawoi).

Lontarak Bilang Raja Gowa dan Tallok (naskah Makassar). (Ujungpandang: Departemen Pendidikan dan Kebudayaan, Bagian Proyek Penelitian dan Pengkajian Kebudayaan Sulawesi Selatan La Galigo, 1986/1987).

Lontarak Catatan Harian Raja Bone.

La Temmasonge' Toappaweling Matinroe ri Mallimongeng.

Lontarak Silsilah Kerajaan Suppa Hubungannya dengan Kerajaan Tellum Boccoe. (Koleksi Yayasan Mappatuju, Makassar).

Kerajaan Tanete dan Hubungannya dengan Kerajaan Tellum Boccoe. (Koleksi Yayasan Mappatuju, Makassar).

\section{Buku}

Abdullah,Taufik. 2005.

Sejarah Lokal di Indonesia, Yogyakarta: UGM Press.

Andaya, Leonard Y. 2004.

Warisan Arung Palakka: Sejarah Sulawesi Selatan Abad ke-17, Makassar: Ininnawa.

Padindang, Ajiep (Peny.). 2007.

Catatan Harian Raja Bone XXII, La Temmassongeng, Makassar: La Macca Press.

Mappangara, Suriadi. 2010.

Kerajaan dan Bangsawan Bone di Tengah Perubahan Rezim (1811-1946). Disertasi. Yogyakarta: Fakultas Ilmu Budaya.

\section{Internet}

Husni, Ahmad. 2011.

Pernikahan Politik dengan Nuansa Politik. Jakarta: http://m.okezone.com/, diunduh tanggal 10 Juni 2012.

Nu'ad, Ismatillah. 2011.

Politik Besan Cikeas. Jakarta:

http://artikelmedia.blogspot.com/, diunduh tanggal 11 Juni 2012. 
